RFP-2914

April 11, 1981

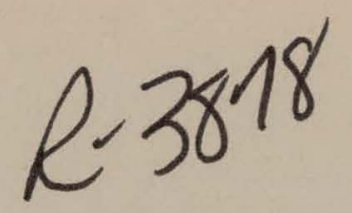

th. 2568

RFP-2914

April 11, 1981

\title{
CALORIMETRY END-POINT PREDICTIONS
}

Michael A. Fox

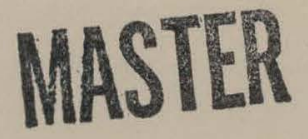

Chemistry R\&D

INSTRUMENT SYSTEMS

\section{Rockwell International}

$$
\begin{aligned}
& \text { Energy Systems Group } \\
& \text { Rocky Flats Plant } \\
& \text { P.O. Box } 464 \\
& \text { Golden, Colorado } 80401
\end{aligned}
$$

U. S. DEPARTMENT OF ENERGY CONTRACT DE-AC04-76DPO3533 


\section{DISCLAIMER}

This report was prepared as an account of work sponsored by an agency of the United States Government. Neither the United States Government nor any agency Thereof, nor any of their employees, makes any warranty, express or implied, or assumes any legal liability or responsibility for the accuracy, completeness, or usefulness of any information, apparatus, product, or process disclosed, or represents that its use would not infringe privately owned rights. Reference herein to any specific commercial product, process, or service by trade name, trademark, manufacturer, or otherwise does not necessarily constitute or imply its endorsement, recommendation, or favoring by the United States Government or any agency thereof. The views and opinions of authors expressed herein do not necessarily state or reflect those of the United States Government or any agency thereof. 


\section{DISCLAIMER}

Portions of this document may be illegible in electronic image products. Images are produced from the best available original document. 


\section{DISCLAIMER}

This report was prepared as an account of work sponsored by an agency of the United States Government. Neither the United States Government nor any agency thereof, nor any of their employees, makes any warranty, express or implied, or assumes any legal liability or responsibility for the accuracy, completeness, or usefulness of any information, apparatus, product, or process disclosed, or represents that its use would not infringe privately owned rights. Reference herein to any specific commercial product, process, or service by trade name, trademark, manufacturer, or otherwise, does not necessarily constitute or imply its endorsement, recommendation, or favoring by the United States Government or any agency thereof. The views and opinions of authors expressed herein do not necessarily state or reflect those of the United States Government or any agency thereof.

Printed in the United States of America

Available from the

National Technical Information Service

U.S. Department of Commerce

Springfield, Virginia 22161

$\begin{array}{cc}\text { Page Range } & \text { Domestic Price* } \\ 001-025 & \$ 5.00 \\ 026-050 & 6.00 \\ 051-075 & 7.00 \\ 076-100 & 8.00\end{array}$

*All microfiche are priced at $\$ 3.50$

Prices Subject to Change Without Notice 


\title{
CALORIMETRY END-POINT PREDICTIONS
}

Michael A. Fox

\author{
Chemistry R\&D
}

INSTRUMENT SYSTEMS

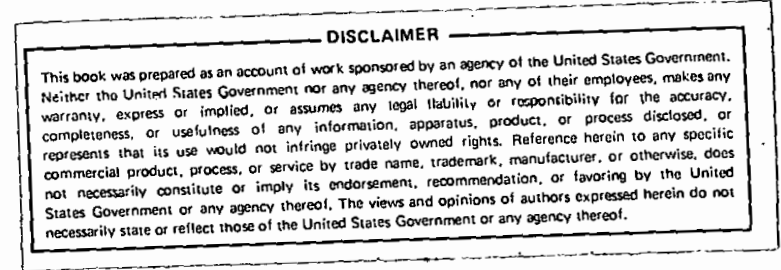

(5) $6^{2}$

\section{SUBJECT DESCRIPTORS}

Calorimetry

End-Puint Predictions

Linear Systems

Steady State Modeling

Heat Transfer

Mathematical/Empirical Modeling Systems Modeling

\footnotetext{
ROCKWELL INTERNATIONAL

ENERGY SYSTEMS GROUP

ROCKY FLATS PLANT

P.O. BOX.464

GOLDEN, COLORADO 80401
}

Prepared under Contract DE-AC04-76DPO3533

for the

Albuquerque Operations Office

U.S. Department of Energy 
RFP-2914 


\section{CONTENTS}

Abstract $\ldots \ldots \ldots \ldots \ldots \ldots \ldots \ldots \ldots \ldots \ldots \ldots \ldots \ldots, 1$

Introduction $\ldots \ldots \ldots \ldots \ldots \ldots \ldots \ldots \ldots \ldots \ldots \ldots, 1$

Background $\ldots \ldots \ldots \ldots, \ldots \ldots \ldots \ldots \ldots \ldots \ldots \ldots, 1$

Development of the Mathematical Description $\ldots \ldots \ldots \ldots \ldots \ldots, 2$

Implementation of Theory and Noise Reduction $\ldots \ldots \ldots \ldots \ldots 13$

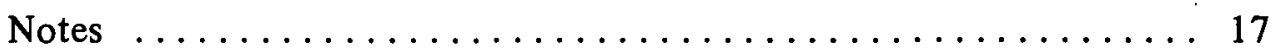

Bibliography $\ldots \ldots \ldots \ldots \ldots \ldots \ldots \ldots \ldots \ldots \ldots \ldots \ldots \ldots$ 
RFP-2914 


\section{A CK N O W LE D GEM EN T S}

I wish to thank the many persons whose technical assistance and advice aided immeasurably in the completion of this work. My appreciation goes particularly to G. P. Minges, J. L. Lawless, J. McBride, R. N. Chanda, J. W. Milan, and K. B. Gerald of the Instrumentation and Statistical Systems Group, and to Professor F. Chernow of the Department of Electrical Engineering at the University of Colorado. 
RFP-2914: 


\title{
CALORIMETRY END-POINT PREDICTIONS
}

\author{
Michael A. Fox
}

\begin{abstract}
The purpose of this paper is to describe a portion of the work presently in progress at Rocky Flats in the field of calorimetry. In particular, calorimetry end-point predictions are outlined. The problems associated with end-point predictions and the progress made in overcoming these obstacles are discussed. The two major problems, noise and an accurate description of the heat function, are dealt with to obtain the most accurate results. Data are taken from an actual calorimeter and are processed by means of three different noise reduction techniques. The processed data are then utilized by one to four algorithms, depending on the accuracy desired to determine the end-point.
\end{abstract}

\section{INTRODUCTION}

The advantages of calorimetry at Rocky Flats have been utilized for the past decade as a means of nondestructive assay of plutonium. Beginning with the advent of the eight-cell isothermal calorimeter designed by F. L. Oetting in $1968,{ }^{*}$ sensitivity and stability in calorimetry has improved with time, culminating with the present two-cell isothermal calorimeter designed by G. P. Minges** and the five-cell isothermal calorimeter designed and built for the new plutonium reprocessing facility at Rocky Flate $\dagger$ Methods of improved stahility and sensitivity have been worked on with considerable success. Because of advances in stability and sensitivity, the rate of throughput, which is disturbingly low, up to 16-24 hours, can now be greatly increased for certain categories of material. One method of increasing throughput involves a mathematical technique known as end-point prediction. End-point prediction has been undertaken with considerable success by Mound

* R. G. White and F. L. Oetting, An Eight Unit Isothermal Calorimeter for Routine Plutonium Analyses, RFP-1401, The Dow Chemical Company, Rucky Flats Division, November 14, 1969.

**G. P. Minges, Rockwell International, Rocky Flats Plant, personal communications, August 3, 1977.

†F. X. Haas et al., Proceedings of the 30th Annual INMM Meeting, July 16-18, 1979.
Laboratory for several years. However, the approximations used in previous work limits the applicability. This paper directs itself towards extending the applicability of end-point prediction by allowing for considerations that previously had not been dealt with.

\section{BACKGROUND}

The process of calorimetry, although very time consuming, is a valuable technique in assessing the power generated by heat sources containing radioactive material.

When a radioactive heat source is placed inside a calorimeter, the temperature within the calorimeter begins to rise. The temperature asymptotically approaches a constant value, and the difference between this asymptotically approached temperature and the temperature when the heat source is not present is directly proportional to the energy output of the heat source. This energy output, in turn, is directly proportional to the mass of the heat generating-or radioactive-material within the heat source. Hence, the temperature differential can be related to the mass of the radioactive material within a heat source. ${ }^{1 *}$

The technique of finding the mass of some radioactive element in a heat source by means of calorimetry has advantages and disadvantages. The technique is accurate but the amount of time required to make an accurate measurement can be excessive. ${ }^{2}$ This time requirement is almost entirely due to the length of time required to let the temperature within the calorimeter reach its asymptotic value. There. are two methods by which this time requirement can be reduced:

1. Speeding-up the asymptotic approach of the temperature within the calorimeter

\footnotetext{
*Superscript numbers appearing in sentences correspond to numbered notations listed at the end of this report.
} 
2. Determining the equilibrium temperature value by consideration of the temperatureversus-time period before the equilibrium value is attained.

The first method involves calorimeter design plus ways to improve upon the construction of devices used in calorimetry. This method will not be dealt with here.

The second method basically involves extrapolating the entire temperature-versus-time curve from a limited set of data. This technique, termed endpoint prediction, is the subject of this report.

To deal with this subject, it is necessary to first adequately describe the temperature within the calorimeter mathematically as a function of time. Secondly, the mathematical description of the temperature-versus-time function must be applied to actual data such that the end-point value may be extrapolated. Hence, this report consists of two parts. The first part details the assumptions and the development of the mathematical description; the second part deals with applying the mathematical description to an actual calorimeter and computer system. Also, the methods used in this system to reduce noise and error inherent in the data are explored.

\section{DEVELOPMENT OF THE MATHEMATICAL DESCRIPTION}

A simple calorimeter can be modeled as a can submerged in an isothermal bath. Inside of the can is a heat source that causes a temperature differential to exist between the inside of the can and the isothermal bath. The can is in actuality the sensor cell, and heat sensing is performed by means of a heat sensor located within the wall of the sensor cell. The heat sensor depicted in Figure 1 is a coil of wire, the resistance of which is almost exactly linearly dependent upon temperature. ${ }^{3}$

If the heat source were not present, then the temperature throughout the system would be that of the isothermal bath. The presence of the heat source causes the temperature of the heat sensor (within the sensor cell wall) to exceed that of the isothermal bath slightly. Since interest lies only in the difference between the equilibrium and initial temperatures, temperature units can be arbitrarily chosen such that the initial temperature (the isothermal bath temperature) is called $0^{\circ}$. For example, if the bath temperature is $290 \mathrm{~K}$, let us denote the temperature of the bath by $0^{\circ}$, which is in units of kelvin minus 290. Thus, other temperatures also would be determined in units of $\mathrm{K}$ minus 290.

By experimentation, the temperature-versus-time function appears as shown in Figure 2.

The function given in Figure 2 can now be determined by use of the model diagrammed in Figure 1.

Let $\alpha$ be the rate at which the heat source is producing heat. The percentage of the total heat in the sensor cell that is transferred to the isothermal bath per unit time is $q_{1}$, and $q_{2}$ is the percentage of total heat in the isothermal bath that is transferred to the sensor cell per unit time. (The resultant net heat flow will, of course, flow from the higher temperature source to the lower temperature source.) The percentage of total heat in the heat source that is transferred to the sensor cell per unit time is $q_{3}$, and $q_{4}$ is the percenlage of total heat in the sensor cell that is transferred to the heat source per unit time. Furthermore, where $Q$ is heat, $T$ is temperature, and $C$ is the specific heat-dQ equals CdT. Let $\mathrm{C}_{\mathrm{C}}$ be the specific heat associated with the sensor cell; let $\mathrm{C}_{\mathrm{S}}$ be the specific heat associated with the heat source; and let $C_{b}$ be the specific heat assuciated with the isothermal bath. If $T_{S}(t)$ is the temperature of the heat source at time $t, T_{b}(t)$ is the temperature of the bath at time $t$, and $T_{c}(t)$ is the temperature of the sensor at time $t$, then

$$
\begin{aligned}
\mathrm{T}_{\mathrm{S}}(\mathrm{t}+\Delta \mathrm{t})= & \mathrm{T}_{\mathrm{S}}(\mathrm{t})+\frac{\alpha}{\mathrm{C}_{\mathrm{S}}}(\Delta \mathrm{t}) \\
& +\frac{\mathrm{q}_{4} \mathrm{C}_{\mathrm{c}}}{\mathrm{C}_{\mathrm{S}}} \mathrm{T}_{\mathrm{c}}(\mathrm{t})(\Delta \mathrm{t}) \\
& -\mathrm{q}_{3} \mathrm{~T}_{\mathrm{S}}(\mathrm{t})(\Delta \mathrm{t})
\end{aligned}
$$




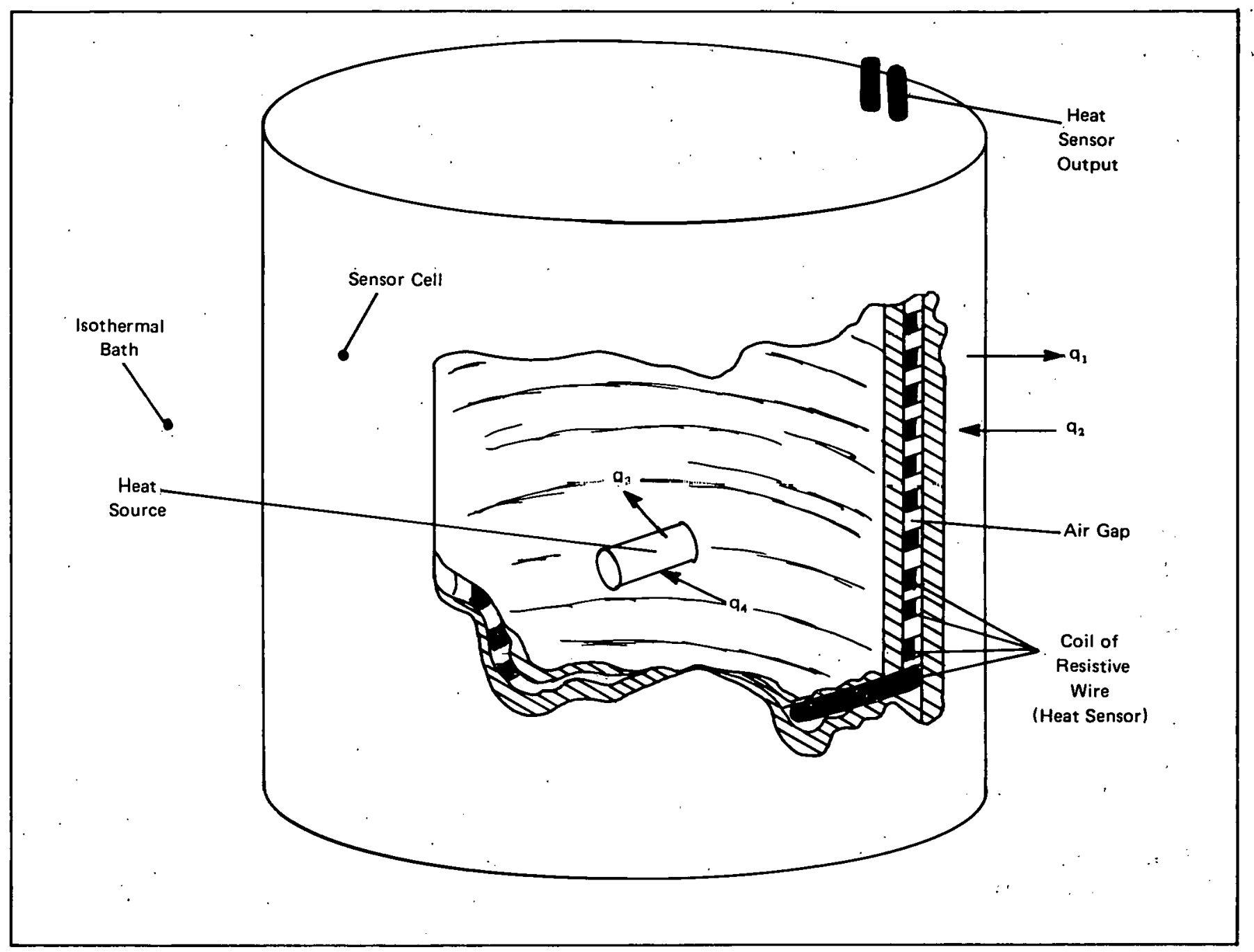

\section{LEGEND}

$\mathrm{q}_{1}$ - heat transfer from sensor cell to isothermal bath

$q_{2}$ - heat transfer from isothermal bath to sensor cell

$\mathrm{q}_{3}$ - heat transfer from heat source to sensor cell

$q_{4}$ - heat transfer from sensor cell to heat source

FIGURE 1. Simple Calorimeter Model 


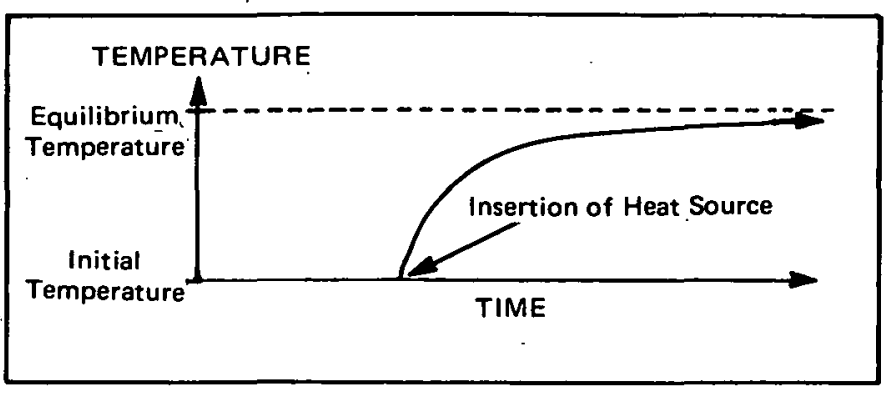

FIGURE 2. Typical Idealized Temperature-Versus-Time Plot

$$
\begin{gathered}
T_{c}(t+\Delta t)=T_{c}(t)+\frac{q_{3} C_{S}}{C_{c}} T_{s}(t)(\Delta t) \\
+\frac{q_{2} C_{b}}{C_{c}} T_{b}(t)(\Delta t) \\
-q_{4} T_{c}(t)(\Delta t) \\
-q_{1} T_{c}(t)(\Delta t) \\
T_{b}(t+\Delta t)=T_{b}(t)+\frac{q_{1} C_{c}}{C_{b}} T_{c}(t)(\Delta t) \\
\quad-q_{\text {total }}(t)=\alpha t+C_{s} T_{s}(0)
\end{gathered}
$$

Equation $1 \mathrm{~d}$ comes from the previous assumption that $\mathrm{T}_{\mathrm{b}}(0)=\mathrm{T}_{\mathrm{c}}(0)=0$ initially.

$$
\begin{aligned}
Q_{\text {total }}(t)= & \alpha t+C_{s} T_{s}(0)+C_{c} T_{c}(0) \\
& +C_{b} T_{b}(0)
\end{aligned}
$$

When the limit is considered as $\Delta \mathrm{t} \rightarrow 0$ of equations $l a, l b$, and $I c$, it is found that

$$
\begin{aligned}
\frac{d T_{S}(t)}{d t}= & \frac{\alpha}{C_{S}}+\frac{q_{4} C_{c}}{C_{S}} T_{c}(t)-q_{3} T_{s}(t) \\
\frac{d T_{c}(t)}{d t}= & \frac{q_{3} C_{S}}{C_{c}} T_{S}(t)+\frac{q_{2} C_{b}}{C_{c}} T_{b}(t) \\
& -q_{1} T_{c}(t)-q_{4} T_{c}(t)
\end{aligned}
$$

$$
\begin{gathered}
\frac{d T_{b}(t)}{d t}=\frac{q_{1} C_{c}}{C_{b}} T_{c}(t)-q_{2} T_{b}(t) \\
Q_{\text {total }}(t)=\alpha t+C_{s} T_{s}(0)
\end{gathered}
$$

The solution of Equations $2 \mathrm{a}$ through $2 \mathrm{~d}$ for $\mathrm{T}_{\mathrm{c}}$ as a function of time is

$$
T_{C}(t)=A+B e^{-p t}
$$

where $A, B$, and $p$ are each a function of the constants appearing in Equatione $2 \mathrm{a}$ through $2 \mathrm{~d}$.

If the temperature of the calorimeter were recorded at times $t_{1}, t_{2}$, and $t_{3}$, where $\left(t_{1}-t_{2}\right)=\left(t_{2}-t_{3}\right)$, then the value of $A$ could be determincd from the following equation: ${ }^{4}$

$$
A=\frac{T_{C}\left(t_{1}\right) T_{C}\left(t_{3}\right)-T_{C}^{2}\left(t_{2}\right)}{T_{C}\left(t_{1}\right)+T_{C}\left(t_{3}\right)-2 T_{C}\left(t_{2}\right)}
$$

This is the equation generally used for end-point prediction. The value $A$ is the limit as $t \rightarrow \infty$ of Equation 3, and $T_{c}(t)$ is the temperature present in the heat sensor. The cquation is certainily nul uniquc; it finds application in many elementary physics, electronics, and flow problems. ${ }^{5}$ Equation 4 is reasonably accurate for most applications, but the model from which it was derived suffers somewhat from oversimplification in this case. Firstly, the previous model assumed that the heat transfer between the heat source and the sensor cell was direct. In reality, the heat source and the sensor cell wall may be separated by some other medium. Secondly, the heat source was treated as a point source while often the heat source may be fragmented or distributed throughout some medium contained by the sensor cell, as illustrated in Figure 3.

Following is a more accurate model in which some additional considerations will be made.

Consider the inside of the sensor cell-containing the heat source and other mediums-as being divided up into n sections. In each section, reference may be made to the rate of heat flow in, the rate of heat flow out, the specific heat, and heat production 


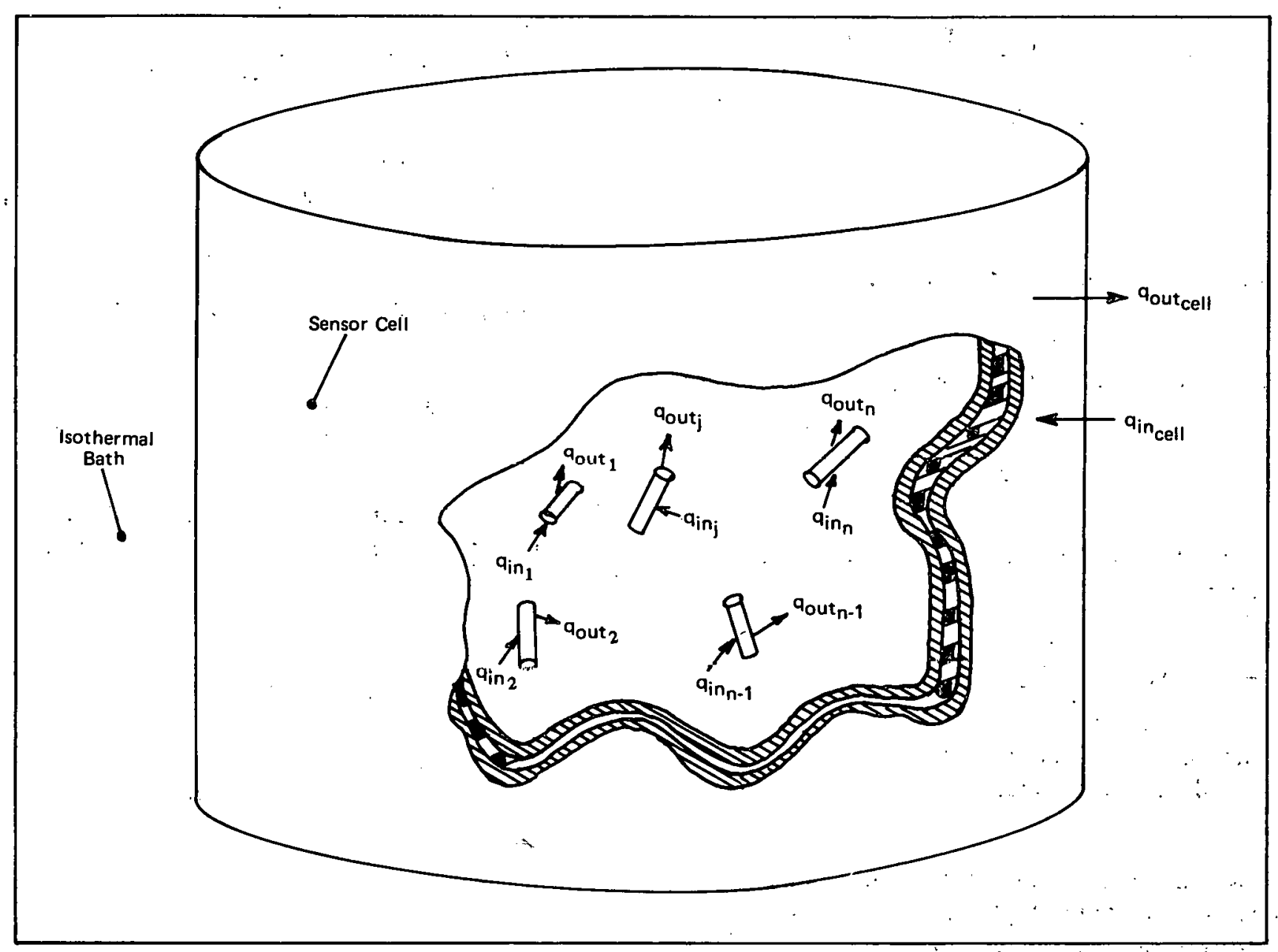

FIGURE 3. Distributed Source Calorimeter Model

(should a heat source happen to be in that particular subdivision). To be accurate, $\mathrm{n}$ must be a fairly large number, thus making the subdivisions fairly small and allowing the association of one specific heat value with any particular subdivision.

This system is most conveniently described by the method of state variables ${ }^{6}$ in which the equation form is

$$
\begin{aligned}
& \dot{T}(t)=A T(t)+B U \\
& T_{c}(t)=C T(t)+D U
\end{aligned}
$$

Here $\mathbf{D}$ is [0] .

Being considered are $\mathrm{n}$ subdivisions within the sensor cell. The sensor cell forms one more subdivision, and the isothermal bath forms yet another subdivision; therefore, there are a total of n-plus- 2 subdivisions and the matrix $\mathbf{A}$ is an n-plus- 2 by $n$-plus- 2 tranșformation matrix. A detailed solution for Equation 5 is not presented; however, the desired results are obtained by considering the characteristic polynomial of the transformation matrix $\mathbf{A}, \mathbf{P}(\mathrm{s})$ equals $\operatorname{det}|s I-\mathbf{A}|$, is of the form

$$
\begin{aligned}
P(s)=s^{n+2}+a_{0} s^{n+1}+a_{1} s^{n}+\ldots & \therefore \\
& +a_{n} s+a_{n+1}
\end{aligned}
$$

The resulting eigenvalues and transfer function for $T_{c}(t)$ imply that the solution of $T_{c}(t)$ is 
RFP-2914.

$$
\begin{aligned}
T_{c}(t)= & -A_{0}-A_{1} e^{-p_{1} t}-A_{2} e^{-p_{2} t} \\
& -A_{3} e^{-p_{3} t}-\ldots \\
& -A_{n+2} e^{-p_{n+2} t}
\end{aligned}
$$

where $A_{i}$ and $p_{i}$ are results of the state variable matrices.?

Since it has been specified that $T_{c}(0)=0$,

$$
\Lambda_{0}=-\sum_{i=1}^{n+2} A_{i}
$$

The equation for the sensor temperature may then be rewritten as

$$
T_{c}(t)=\sum_{i=1}^{n+2} A_{i}\left(1-e^{-p_{i} t}\right)
$$

Equation 8 is a generalized result. To make it useful, conditions met with in calorimetry must be specified. ${ }^{8}$

A few statements can be made about the $A_{i}$ 's and the $p_{i}$ 's appearing in Equation 8. Since the system being discussed reaches a finite equilibrium value as $t \rightarrow \infty$, it is imperative that all the values of $p_{i}$ be positive. Also, since $T_{c}(t)$ is an increasing function with increasing time, it is necessary to say that all the $A_{i}$ values also are positive. If there were to exist an $A_{i}$ that was negative, then some part of the system would be cooling down, which is not the case.

Since the summation in Equation 8 is difficult to handle, it is convenient to convert the summation to an integral form. Thus, a function $\phi$ (i) shall be defined such that for any $i$,

$$
\phi(i)=\frac{A_{i}}{\sum_{j=1}^{n+2}} A_{j} \text {, and } \phi(i)=0 \text { for } 0 \geqslant i>n+2
$$

Equation 8 may be rewritten so as to read

$$
\mathrm{T}_{c}(\mathrm{t})=\sum_{\mathrm{i}=1}^{\mathrm{n}+2} \mathrm{~A}_{\mathrm{i}} \sum_{\mathrm{i}=1}^{\mathrm{n}+2} \phi(\mathrm{i})\left(1-\mathrm{e}^{-\mathrm{p}_{\mathrm{i}} \mathrm{t}}\right)
$$

If $\Lambda$ is defined such that $\Lambda=\sum_{i=1}^{n+2} A_{i}$, then

$$
\mathrm{T}_{c}(\mathrm{t})=\Lambda \sum_{\mathrm{i}=1}^{\mathrm{n}+2} \phi(\mathrm{i})\left(1-\mathrm{e}^{-\mathrm{p}_{\mathrm{i}} \mathrm{t}}\right)
$$

A function, $\theta(p)$, now is defined such that

$$
\theta(p)=\sum_{i=1}^{n+2} \phi(i) \delta\left(p-p_{i}\right)
$$

where $\delta(p)$ is the delta function. ${ }^{9}$ The definition of $\theta(p)$ allows the conversion of Equation 8 to an integral form where

$$
T_{c}(t)=\Lambda \sum_{i=1}^{n+2} \phi(i)\left(1-e^{-p_{i} t}\right)
$$

$$
=\Lambda \int_{0}^{\infty} \theta(p)\left(1-e^{-p t}\right) d p
$$

$$
T_{c}(t)=\Lambda \int_{0}^{\infty} \theta(p)\left(1-e^{-p t}\right) d p
$$

$\theta(p)$ is simply the sum of n-plus-2 delta functions. The delta functions are positioned at the $p_{i}$ 's with intensity $\phi(i), \theta(p)$ also has the property

$$
\int_{0}^{\infty} O(p) d p=1
$$

provided by Equation 9 and provided simply for convenience.

For any system of heat sources within a calorimeter, there is an associated $\theta(p)$ that precisely describes the system externally. However, the problem is that for any given system, the $\theta(p)$ is exceedingly difficult to determine. In fact, given a system with its associated $\theta(\mathrm{p})$, a minor change in the placement of the heat source(s) associated with that system may well result in a major change in the associated $\theta(\mathrm{p})$. 
Since it is necessary to evaluate Equation 14 such that end-point prediction is possible, it is necessary to find a general equation that will evaluate $\theta(p)$ or closely approximate it. Therefore, assume that there exists a function $\xi\left(\mathrm{p}, \mathrm{u}_{1}, \mathrm{u}_{2}, \mathrm{u}_{3}, \ldots, \mathrm{u}_{\mathrm{m}}\right)$ such that given the $\theta(\mathrm{p})$ for some system, the parameters $u_{1}, u_{2}, u_{3}, \ldots, u_{m}$ can be chosen such that, to within a close approximation, ...

$$
\begin{gathered}
\Lambda \int_{0}^{\infty} \xi\left(p, u_{1}, u_{2}, u_{3}, u_{4}, \ldots, u_{m}\right) \cdot\left(1-e^{-p_{i} t}\right) d p \\
\simeq \Lambda \int_{0}^{\infty} \theta(p)\left(1-e^{-p t}\right) d p=T_{c}(t)
\end{gathered}
$$

The shape of the function $\xi\left(p, u_{1}, u_{2}, u_{3}, \ldots, u_{m}\right)$ is controlled by the parameters $u_{1}, u_{2}, u_{3}, \ldots$, and $u_{m}$. The variability of the function is determined by the number of controlling paramèters. Hence, the larger the value of $m$, the greater the potential for variability-though not necessarily accuracy.

The problem that remains is to find the function $\xi\left(p, u_{1}, u_{2}, u_{3}, \ldots, u_{m}\right)$ such that the chosen function applies to the maximum number of situations with a minimum quantity of error and a minimum number of controlling parameters, each of which should be easily evaluated.

To minimize the number of controlling parameters and minimize the error, it is best to choose a $\xi\left(p, u_{1}, u_{2}, u_{3}, \ldots, u_{m}\right)$, the general shape of which is already a fair approximation to most $\theta(p)$ functions.

Since the exponential functions specified by $\xi\left(p, u_{1}, u_{2}, u_{3}, \ldots, u_{m}\right)$ will, in general, be different from those spccificd by $\theta(p)$-especially when the number of controlling parameters, $m$, is small - it would be beneficial to consider the approximation of one exponential by the sum of other exponentials.

Considering the approximation of one exponential function by the sum of two exponential functions is sufficient to tell us a little more about the function $\xi\left(\mathrm{p}, \mathrm{u}_{1}, \mathrm{u}_{2}, \mathrm{u}_{3}, \ldots, \mathrm{u}_{\mathrm{m}}\right)$.
Define $\mathrm{p}_{1}, \mathrm{p}_{2}, \mathrm{p}_{0}, \mathrm{M}$, and $\mathrm{N}$ such that

$$
\begin{aligned}
&\left(1-\mathrm{e}^{-p_{0} t}\right) \simeq M\left(1-\mathrm{e}^{-p_{1} t}\right) \\
&+N\left(1-e^{-p_{2} t}\right)
\end{aligned}
$$

where $p_{1} \neq p_{0} \neq p_{2}$. By considering the limit when $t \rightarrow \infty$, it is found that $N=1-M$, hence

$$
\begin{aligned}
\left(1-e^{-p_{0} t}\right) \simeq M\left(1-e^{-p_{1} t}\right) & \\
& +(1-M)\left(1-e^{-p_{2} t}\right)
\end{aligned}
$$

from which it follows that

$$
\mathrm{e}^{-\mathrm{p}_{0} \mathrm{t}} \simeq \mathrm{Me}^{-\mathrm{p}_{1} \mathrm{t}}+(1-\mathrm{M}) \mathrm{e}^{-\mathrm{p}_{2} \mathrm{t}}
$$

To consider the error that is encountered, $\epsilon(t)$ is defined such that

$$
\epsilon(t)+e^{-p_{0} t}=M e^{-p_{1} t}+(1-M) e^{-p_{2} t}
$$

By considering $\partial \epsilon(t) / \partial \mathrm{p}_{1}$ and $\partial \epsilon(\mathrm{t}) / \partial \mathrm{p}_{2}$, it may be observed that the error, with respect to these two variables, is kept to a minimum by making $p_{1}$ and $p_{2}$ as close to $p_{0}$ as possible. The value $\epsilon^{2}(t)$ may be considered as follows:

$$
\begin{aligned}
\epsilon^{2}(t)= & M^{2} e^{-2 p_{1} t}+(1-M)^{2} e^{-2 p_{2} t} \\
& +e^{-2 p_{0} t}+2 M(1-M) e^{-\left(p_{1}+p_{2}\right) t} \\
& -2 M e^{-\left(p_{1}+p_{0}\right) t}-2(1-M) e^{-\left(p_{2}+p_{0}\right) t} \\
\int_{0}^{\infty} \epsilon^{2}(t) & =\frac{M^{2}}{2 p_{1}}+\frac{(1-M)^{2}}{2 p_{2}}+\frac{1}{2 p_{0}}+\frac{2 M(1-M)}{\left(p_{1}+p_{2}\right)} \\
& -\frac{2 M}{p_{1}+p_{0}}-\frac{2(1-M)}{p_{0}+p_{2}}
\end{aligned}
$$

Setting $\partial / \partial M \int_{0}^{\infty} \epsilon^{2}(t) d t=0$, to minimize the error over all time with respect to $M$, gives

$$
M=\frac{\frac{2}{p_{1}+p_{0}}-\frac{2}{p_{2}+p_{0}}-\frac{2}{p_{1}+p_{2}}+\frac{1}{p_{2}}}{\frac{1}{p_{1}}+\frac{1}{p_{2}}-\frac{4}{p_{1}+p_{2}}}
$$


which is by no means a constant. It also demonstrates the interdependence of the variables. In fact, continued analysis shows that when $2\left[\left(p_{2}-p_{1}\right) /\left(p_{1}+p_{2}\right)\right] \ll 1$, then $M$ can take on almost any value, depending upon slight variations of $\mathrm{p}_{1}$ and $\mathrm{p}_{2}$.

The approximation holds best when $t$ is small and also when $t \rightarrow \infty$, which is sufficient since the data that will be considered is from when $t$ is small, and the end-point occurs when $t \rightarrow \infty$.

From the brief discussion of two exponentials being used to approximate a single exponential, it can be shnwn that

$$
\begin{gathered}
\int_{0}^{\infty} \xi\left(p, u_{1}, u_{2}, u_{3}, \ldots, u_{m}\right) d p \\
=\int_{0}^{\infty} \theta(p) d p=1
\end{gathered}
$$

and $\xi\left(\mathrm{p}, \mathrm{u}_{1}, \mathrm{u}_{2}, \mathrm{u}_{3}, \ldots, \mathrm{u}_{\mathrm{m}}\right)$ should look similar to $\theta(p)$ such that maximums of $\theta(p)$ should correspond. to maximums of $\xi\left(p, u_{1}, u_{2}, u_{3}, \ldots, u_{m}\right)$. Furthermore, the majority, if not all, of the function

$\xi\left(\mathrm{p}, \ddot{\mathrm{u}}_{1}, \mathrm{u}_{2}, \mathrm{u}_{3}, \ldots, \mathrm{u}_{\mathrm{m}}\right)$ should occur between the limits of $\mathrm{p}_{\min }$ and $\mathrm{p}_{\max }$.

For our purposes, let us choose $m=2$ and consider a hypothetical, typical $\theta(\mathrm{p})$. function. Graphically, a hypothetical $\theta(p)$ versus $\left(1-e^{-p t_{0}}\right)$, where $t_{0}$ is some constant, might appear as in Figure 4.

Consider now, a possible distribution for $\xi\left(p, u_{1}\right.$, $u_{2}$ ) graphed over the $\theta(p)$ function, as in Figure 5.

Here $\xi\left(p, u_{1}, u_{2}\right)$ is chosen to be normal in the $\theta(\mathrm{p}),\left(1-\mathrm{e}^{-\mathrm{pt}_{0}}\right)$ plane; hence where $\gamma=\left(1-\mathrm{e}^{-\mathrm{pt}_{0}}\right)$, $\mathrm{u}_{1}=\mu$ and $\mathrm{u}_{2}=\sigma$,

$$
\xi(\mathrm{p}, \mu, \sigma) \mathrm{dp}=\frac{\mathrm{e}^{\frac{-(\gamma-\mu)^{2}}{2 \sigma^{2}}}}{\sqrt{2 \pi \sigma}} \frac{1}{\left[\mathrm{~F}\left(\frac{\mu}{\sigma}\right)-\mathrm{F}\left(\frac{\mu-1}{\sigma}\right)\right]} \mathrm{d} \gamma
$$

The quantity $1 /\{\mathrm{F}[\mu / \sigma]-\mathrm{F}[(\mu-1) / \sigma]\}$ is merely a constant such that Equation 16 is satisfied.

\footnotetext{
*See Note 10 at the end of this report.
}

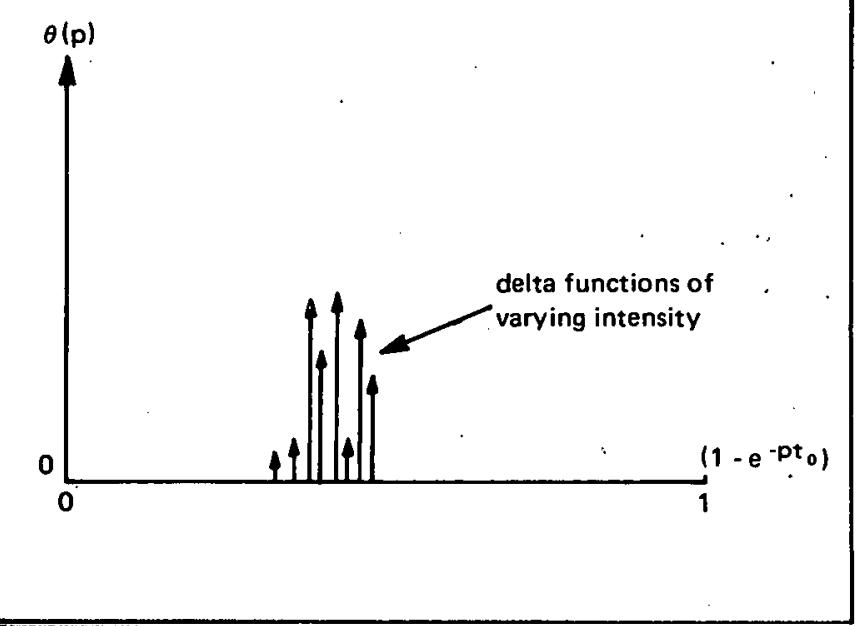

FIGURE 4. Hypothetical Graph of $\theta(p)$ Versus $\left(1-e^{-p t_{0}}\right)$

FIGURE 5. Example of a Hypothetical $\xi\left(p, u_{1}\right.$, $\mathrm{u}_{2}$ ) Function Being Used to Approximate $\theta(\mathrm{p})$

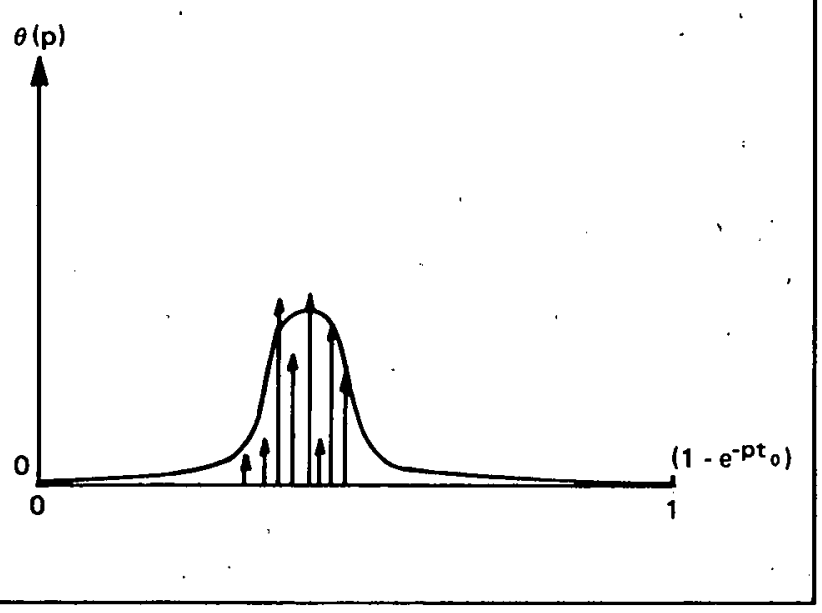

This particular choice of $\xi\left(p, u_{1}, u_{2}\right)$ possesses two important qualities. First, the function generally proves to be an accurate approximation to the sum of several exponential functions, even when the number of exponential functions is as low as two. Secondly, the values of $\mu$ and $\sigma$ needed to reduce to a minimum the error for any particular $\theta(p)$ function can be determined. However, it does prove necessary to determine $\mu$ and $\sigma$ by successive approximation, which is a little more tedious than a direct calculation. The function is not a unique solution for $\xi\left(p, u_{1}, u_{2}\right)$ but because of the sufficient 
variability of the function because of the controlling parameters $\mu$ and $\sigma$, and the fact that an exponential function can be closely approximated by the sum of exponential functions, the normal function proves to be accurate.

Consideration might also be given to Figure 6 in which

$$
\begin{aligned}
\xi\left(\mathrm{p}, \gamma_{\min }, \gamma_{\max }\right) \mathrm{dp} & \\
\quad= & \frac{\pi}{2\left(\gamma_{\max }-\gamma_{\min }\right)} \sin \pi \frac{\gamma-\gamma_{\min }}{\gamma_{\max }-\gamma_{\min }} \mathrm{d} \gamma
\end{aligned}
$$

where

$$
\gamma_{\min } \leqslant \gamma \leqslant \gamma_{\max }
$$

In this case,

$$
u_{1}=\gamma_{\text {IIldx }} \text { and } u_{3}=\gamma_{\text {Inin }}
$$

where

$$
\gamma=\left(1-\mathrm{e}^{-\mathrm{pt}_{0}}\right)
$$

This function also proves to be an accurate representation of the sum of exponential functions. for the same reasons that Equation 17 proves to be accurate. Again $\gamma_{\min }$ and $\gamma_{\max }$ can be found such that the error is minimized for any particular $\theta(p)$ function.

Equation 15 can now be solved using each of these two functions.

From Equation 17,

$$
\xi(\mathrm{p}, \mu, \sigma)=\frac{\mathrm{e}^{\frac{-(\gamma-\mu)^{2}}{2 \sigma^{2}}}}{\sqrt{2 \pi} \sigma\left[\mathrm{F}\left(\frac{\mu}{\sigma}\right)-\mathrm{F}\left(\frac{\mu-1}{\sigma}\right)\right]}\left(\frac{\mathrm{d} \gamma}{\mathrm{dp}}\right)
$$

where $\gamma=1-\mathrm{e}^{-\mathrm{pt}}$

Since $d \gamma / d p=t_{0} e^{-p t_{0}}$, then

$$
\xi(\mathrm{p}, \mu, \sigma)=\frac{\mathrm{t}_{0} \mathrm{e}^{-\mathrm{pt}_{0}} \mathrm{e}^{\frac{-\left[\mathrm{e}^{-\mathrm{pt}_{0}}-(1-\mu)\right]^{2}}{2 \sigma^{2}}}}{\sqrt{2 \pi} \sigma\left[\mathrm{F}\left(\frac{\mu}{\sigma}\right)-\mathrm{F}\left(\frac{\mu-1}{\sigma}\right)\right]}
$$

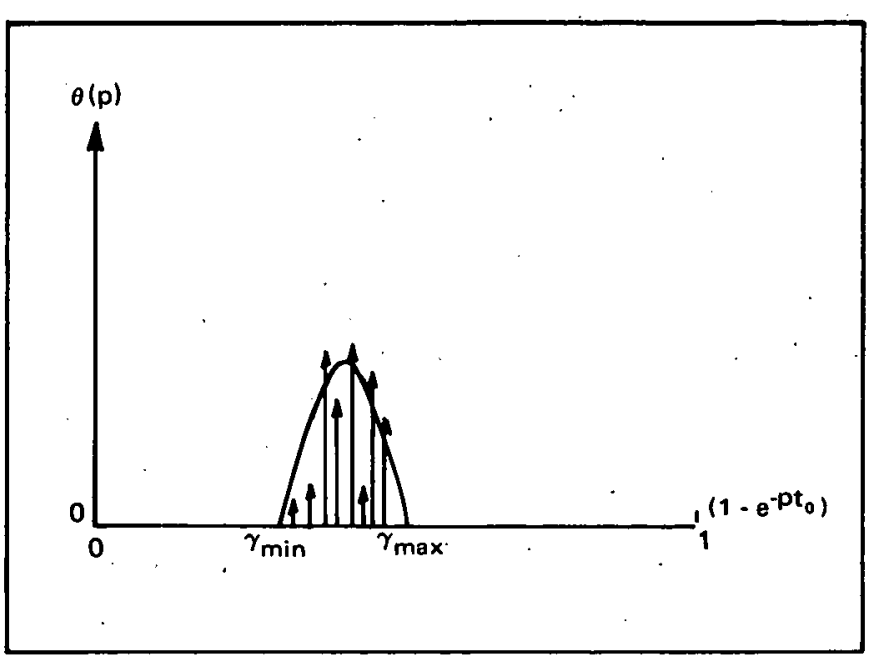

FIGURE 6. Another Hypothetical $\xi\left(\mathrm{p}, \mathrm{u}_{1}, \mathrm{u}_{2}\right)$ Function Being Used to Approximate $\theta(\mathrm{p})$

By substituting Equation 19 into Equation 15, the following is obtained:

$$
T_{c}(t) \simeq \Lambda \int_{0}^{\infty} \frac{t_{0} e^{-p t_{0}} \cdot e^{\frac{-\left[e^{-p t_{0}}-(1-\mu)\right]^{2}}{2 \sigma^{2}}}}{\sqrt{2 \pi} \sigma\left[F\left(\frac{\mu}{\sigma}\right)-F\left(\frac{\mu-1}{\sigma}\right)\right]}\left(1-e^{-p t}\right) d p
$$

The difficulty of this integral is reduced by letting $y=e^{-p t_{0}}$ such that $d y=t_{0} e^{-p t_{0}} d p$.

$$
T_{c}(t) \simeq \Lambda \int_{0}^{1} \frac{e^{\frac{-[y-(1-\mu)]^{2}}{2 \sigma^{2}}}}{\sqrt{2 \pi} \sigma\left[F\left(\frac{\mu}{\sigma}\right)-F\left(\frac{\mu-1}{\sigma}\right)\right]}\left(1-y^{\frac{t}{t_{0}}}\right) d y
$$

Using Equation 16, a further reduction is possible:

$$
\mathrm{T}_{\mathrm{C}}(\mathrm{t}) \simeq \Lambda-\Lambda \int_{0}^{1} \frac{\mathrm{e}^{\frac{-[\mathrm{y}-(1-\mu)]^{2}}{2 \sigma^{2}}}}{\sqrt{2 \pi} \sigma\left[\mathrm{F}\left(\frac{\mu}{\sigma}\right)-\mathrm{F}\left(\frac{\mu-1}{\sigma}\right)\right]} \mathrm{y}^{\frac{\mathrm{t}}{\mathrm{t}_{0}}} \mathrm{dy}
$$

Now this integral cannot be solved for any time $t$ in gencral; however, it can be solved for times when $t$ is an integer multiple of some time $t_{0}$. 
The solution is found to be

$$
T_{c}(t)=\Lambda[1-\Psi(t)]
$$

where $\Psi(0)=1$

$$
\Psi\left(t_{0}\right)=(1-\mu)+\frac{\sigma\left[\mathrm{e}^{\frac{-(1-\mu)^{2}}{2 \sigma^{2}}}-\mathrm{e}^{\left.\frac{-\mu^{2}}{2 \sigma^{2}}\right]}\right.}{\sqrt{2 \pi}\left[\mathrm{F}\left(\frac{\mu}{\sigma}\right)-\mathrm{F}\left(\frac{\mu-1}{\sigma}\right)\right]}
$$

and in general

$$
\begin{gathered}
\Psi\left(t+2 t_{0}\right)=\left(1+\frac{t}{t_{0}}\right) \sigma^{2} \Psi(t)+(1-\mu) \Psi\left(t+t_{0}\right) \\
\quad: \frac{\sigma e^{\frac{-\mu^{2}}{2 \sigma^{2}}}}{\sqrt{2 \pi}\left[F\left(\frac{\mu}{\sigma}\right)-F\left(\frac{M=1}{\sigma}\right)\right]}
\end{gathered}
$$

As $\sigma \rightarrow 0$, the previous equations reduce to a single exponential function.

$$
\lim _{\sigma \rightarrow 0} \mathrm{~T}_{\mathrm{C}}(\mathrm{t})=\Lambda\left[1-(1-\mu)^{\frac{\mathrm{t}}{\mathrm{t}_{0}}}\right]
$$

Although it is not obvious from Equation 20,

$$
\begin{array}{ll} 
& \lim _{t \rightarrow \infty} \Psi(\mathrm{t})=0 \\
\text { therefore } \quad & \because \because \\
& \lim _{\mathrm{t} \rightarrow \infty} \mathrm{T}_{\mathrm{c}}(\mathrm{t})=\Lambda
\end{array}
$$

Equation 18 can be used to solve Equation 15. The following can be found from Equation 18:

$$
\begin{aligned}
& \xi\left(\mathrm{p}, \gamma_{\min }, \gamma_{\max }\right) \\
& =\frac{\pi \mathrm{t}_{\mathrm{n}} \mathrm{e}^{-\mathrm{pt} t_{0}}}{2\left(\gamma_{\max }-\gamma_{\min }\right)} \sin \pi \frac{1-\mathrm{e}^{-\mathrm{pt}_{0}}-\gamma_{\min }}{\gamma_{\max }-\gamma_{\min }}
\end{aligned}
$$

Again, substitution into Equation 15 enables the following to be obtained:

$$
\begin{aligned}
\mathrm{T}_{\mathrm{c}}(\mathrm{t}) \simeq \Lambda \int_{\mathrm{p}_{\min }}^{\mathrm{p}_{\max }} \frac{\mathrm{t}_{0} \mathrm{e}^{-\mathrm{pt}_{0} \pi}}{2\left(\gamma_{\max }-\gamma_{\min }\right)} \\
\quad \cdot \sin \pi \frac{1-\mathrm{e}^{-\mathrm{pt} \mathrm{t}_{0}}-\gamma_{\min }}{\gamma_{\max }-\gamma_{\min }}\left(1-\mathrm{e}^{-\mathrm{pt}}\right) \mathrm{dp}
\end{aligned}
$$

Letting $\mathrm{y}=\mathrm{e}^{-\mathrm{pt}}$,

$$
\begin{aligned}
& \mathrm{T}_{\mathrm{c}}(\mathrm{t}) \simeq \Lambda \int_{1-\gamma_{\min }}^{1-\gamma_{\max }} \frac{-\pi}{2\left(\gamma_{\max }-\gamma_{\min }\right)} \\
& \sin \left(\pi \frac{1-\mathrm{y}-\gamma_{\min }}{\gamma_{\max }-\gamma_{\min }}\right)\left(1-\frac{\mathrm{t}}{\mathrm{t}_{0}}\right) \mathrm{dy} \\
& \mathrm{T}_{\mathrm{c}}(\mathrm{t}) \simeq \Lambda+\Lambda \int_{1-\gamma_{\max }}^{1-\gamma_{\min }} \frac{\pi \frac{\mathrm{t}}{\mathrm{t}_{\mathrm{o}}}}{2\left(\gamma_{\max }-\gamma_{\min }\right)} \\
& \sin \pi \frac{\mathrm{y}+\gamma_{\min }-1}{\gamma_{\max }=\gamma_{\min }} \mathrm{dy}
\end{aligned}
$$

$\Lambda$ gain, this is a function which can only be solved when $t$ is an integer multiple of $t_{0}$.

$$
\mathrm{T}_{\mathrm{c}}(\mathrm{t})=\Lambda\left[1-\Xi\left(\frac{\mathrm{t}}{\mathrm{t}_{0}}\right)\right]
$$

where $\Xi(0)=1$

and

$$
\begin{aligned}
& \Xi\left(\frac{t}{t_{0}}+2\right) \\
&=\frac{1}{2}\left(1-\gamma_{\min }\right)^{\frac{t}{t_{0}}+2}+\frac{1}{2}\left(1-\gamma_{\max }\right)^{\frac{t}{t_{0}}+2} \\
&-\left(\frac{\gamma_{\max }-\gamma_{\min }}{\pi}\right)^{2}\left(1+\frac{t}{t_{0}}\right)\left(2+\frac{t}{t_{0}}\right) \Xi\left(\frac{t}{t_{0}}\right)
\end{aligned}
$$

Another possible form of $\xi\left(p, u_{1}, u_{2}, u_{3}, \ldots, u_{m}\right)$ can be detcrmined by again referring to Figure 4 .

Suppose that $\xi\left(p, u_{1}, u_{2}, u_{3}, \ldots, u_{m}\right)$ is the sum of a finite number of exponential functions. The distribution shown in Figure 7 can be approximated by the distribution indicated in Figure 8 .

The function, $T_{c}(t)$, that could result is

$$
T_{c}(t) \simeq A+B_{0} e^{-\lambda t}+B_{1} e^{-(\lambda+k) t}+B_{2} e^{-(\lambda+2 k) t}
$$

where $\lambda, k, A, B_{0}, B_{1}$, and $B_{2}$ are chosen to yield the best approximation to $\mathrm{T}_{\mathrm{C}}(\mathrm{t})$. 


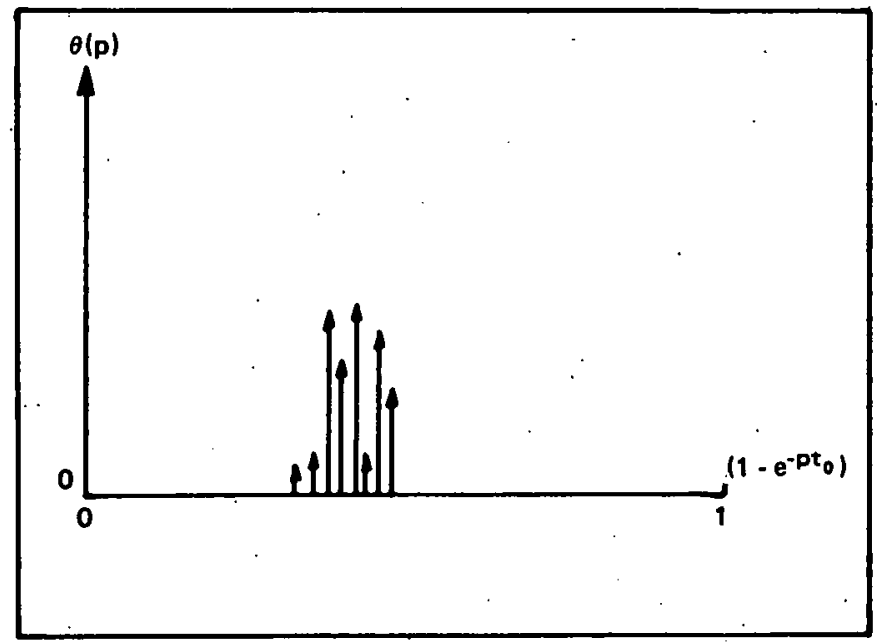

FIGURE 7. Hypothetical $O(p)$ Function

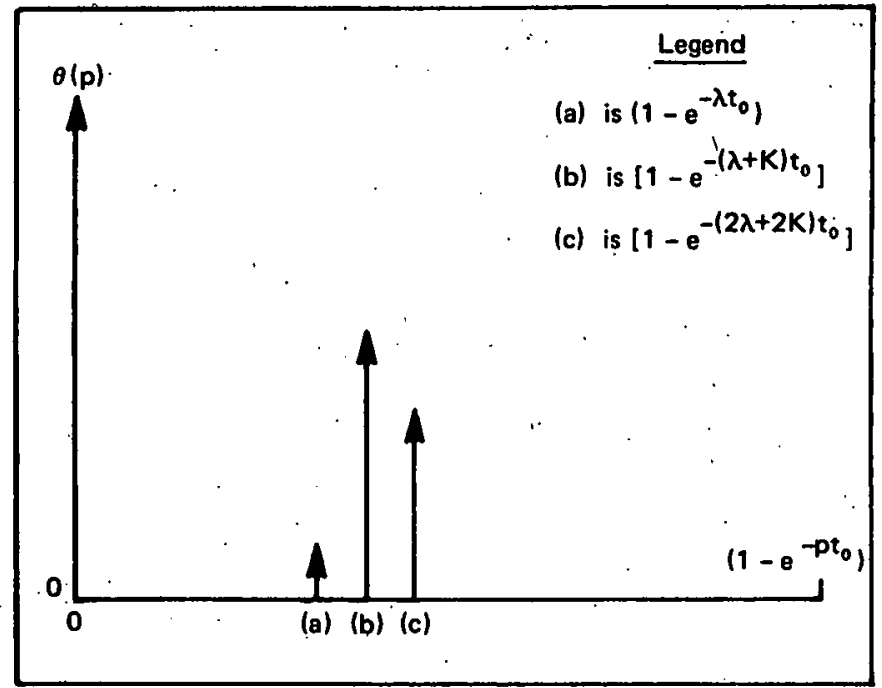

FIGURE 8. Approximation of

$\theta(p)$ by Three Delta Functions.

By recording values of $T_{c}(t)$ at five equally spaced times, $f_{1}, f_{2}, f_{3}, f_{4}$, and $f_{5}$ can be defined as

$$
\begin{aligned}
& \mathrm{f}_{1}=T_{c}\left(t_{1}\right) \\
& f_{2}=T_{c}\left(t_{1}+\Delta t\right) \\
& f_{3}=T_{c}\left(t_{1}+2 \Delta t\right) \\
& f_{4}=T_{c}\left(t_{1}+3 \Delta t\right) \\
& f_{5}=T_{c}\left(t_{1}+4 \Delta t\right)
\end{aligned}
$$

If $\omega=k / \lambda$, then

$$
\begin{aligned}
& f_{1}=A+B_{0} e^{-\lambda t}+B_{1} e^{-\lambda(1+\omega) t}+B_{2} e^{-\lambda(1+2 \omega) t} \\
& f_{2}=A+B_{0} e^{-\lambda(t+\Delta t)}+B_{1} e^{-\lambda(1+\omega)(t+\Delta t)}+B_{2} e^{-\lambda(1+2 \omega)(t+\Delta t)} \\
& f_{3}=A+B_{0} e^{-\lambda(t+2 \Delta t)}+B_{1} e^{-\lambda(1+\omega)(t+2 \Delta t)}+B_{2} e^{-\lambda(1+2 \omega)(t+2 \Delta t)} \\
& f_{4}=A+B_{0} e^{-\lambda(t+3 \Delta t)}+B_{1} e^{-\lambda(1+\omega)(t+3 \Delta t)}+B_{2} e^{-\lambda(1+2 \omega)(t+3 \Delta t)} \\
& f_{5}=A+B_{0} e^{-\lambda(t+4 \Delta t)}+B_{1} e^{-\lambda(1+\omega)(t+4 \Delta t)}+B_{2} e^{-\lambda(1+2 \omega)(t+4 \Delta t)}
\end{aligned}
$$


By letting $\beta=\mathrm{B}_{0} \mathrm{e}^{-\lambda \mathrm{t}}, \theta=\mathrm{B}_{1} \mathrm{e}^{-(1+\omega) \lambda \mathrm{t}}, \mathrm{Z}=\mathrm{B}_{2} \mathrm{e}^{-(1+2 \omega) \lambda \mathrm{t}}$, and $\eta=\mathrm{e}^{-\lambda(\dot{\mathrm{t}})}$, then $\mathrm{A}$ can be solved.

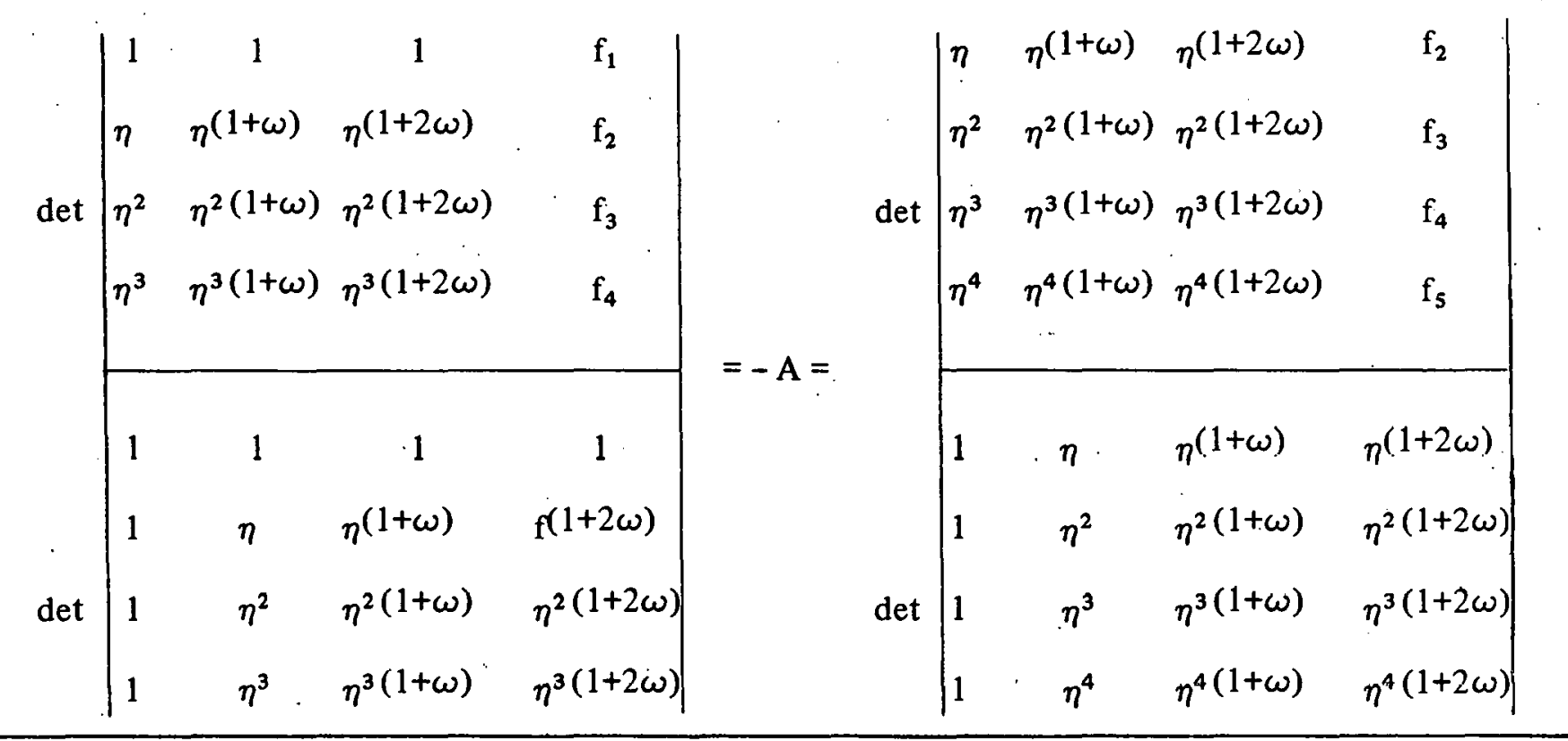

From this, two equations can be obtained:

$$
\begin{aligned}
& \left(\mathrm{f}_{4}-\mathrm{f}_{5}\right)-\eta\left(\mathrm{f}_{3}-\mathrm{f}_{4}\right)\left(\eta^{2} \omega+\eta \omega+1\right) \\
& +\eta^{2+} \omega\left(\mathrm{f}_{2}-\mathrm{f}_{3}\right)\left(\eta^{2} \omega+\eta \eta^{2}+1\right) \\
& -\eta^{3+3} \omega_{\left(\mathrm{f}_{1}-\mathrm{f}_{2}\right)=0} \\
& {\left[\mathrm{f}_{4}-\mathrm{f}_{3} \eta\left(\eta^{2} \omega+\eta \omega+1\right)\right.} \\
& +\mathrm{f}_{2} \eta^{2+\omega}\left(\eta^{2} \omega+\eta^{\omega}+1\right) \\
& \left.-\mathrm{f}_{1} \eta^{3+3} \omega\right] /[(1-\eta) \\
& \left.\times\left(1-\eta^{1+\omega}\right)\left(1-\eta^{1+2} \omega\right)\right]=A
\end{aligned}
$$

For all applications here, the value of $\omega$ will be 1 . This choice stems from two advantages:

1. The value, $\omega=1$, proves to be a good choice empirically.

2. Since this equation is being developed such that it may be used in a computer, $\omega$ being an integer allows a significant increase in computing speed.
For $\omega=1$,

$$
\begin{aligned}
& \left(\mathrm{f}_{4}-\mathrm{f}_{5}\right)-\left(\mathrm{f}_{3}-\mathrm{f}_{4}\right)\left(\eta^{3}+\eta^{2}+\eta\right) \\
& -\left(\dot{\mathrm{f}}_{2}-\mathrm{f}_{3}\right)\left(\eta^{5}+\eta^{4}+\eta^{3}\right) \\
& -\left(\mathrm{f}_{1}-\mathrm{f}_{2}\right) \eta^{6}=0 \\
& {\left[\mathrm{f}_{4}-\mathrm{f}_{3}\left(\eta^{3}+\eta^{2}+\eta\right)\right.} \\
& \left.+\mathrm{f}_{2}\left(\eta^{5}+\eta^{4}+\eta^{3}\right)-\mathrm{f}_{1} \eta^{6}\right] /[(1-\eta) \\
& \left.\times\left(1-\eta^{2}\right)\left(1-\eta^{3}\right)\right]=A
\end{aligned}
$$

By collecting the data points, $f_{1}, f_{2}, f_{3}, f_{4}$, and $f_{5}$, and solving Equation 25a for $\eta$ (which, by definition, is always a value between 0 and 1 ) and then substituting the roots of Equation 25a into Equation $25 \mathrm{~b}$, the value A can be determined. Of course, from Equation 23 it is shown that the limit of $T_{c}(t)$ approaching infinity is equal to $A$; hence the value $A$ is the desired equilibrium temperature.

Equations 4, 20, 22, and 25 have been applied to actual data to perform end-point predictions. The next section describes a calorimeter system, 
implementation of the equations developed here, and noise reduction techniques used in an existing computer program.

\section{IMPLEMENTATION OF THEORY AND NOISE REDUCTION}

Figure 9 illustrates schematically a calorimeter system that presently. exists. ${ }^{11}$.

The heat sensor is simply a wire resistor within the sensor cell wall, the resistance of which changes as a function of temperature. The resistance is not perfectly linear with temperature, therefore some adjustments are made to the data after the data are compiled. The adjustments compensate for any nonlinearities. The calculator controls the scanner, which chooses which resistor the digital voltmeter (D.V.M.) will be looking at by closing appropriate switches internally. The resistance is measured in 4-wire ohms to obtain higher accuracy; the scanner utilizes low, thermal, electromotive force relays. The D.V.M. sends data to the calculator where the data are collected and two noise-reduction techniques are employed. The calculator also monitors a reference cell to ensure that the isothermal bath is functioning. After receiving a sufficient quantity of data, the calculator transmits the collected data to the computer, which then performs the endpoint predictions and communicates with the operator via the line printer and cathode ray tube (C.R.T.) terminal.

Between the calorimeters and the output, many things happen to the data. First to take place are the noise reduction techniques:

1. Nonlinear digital low-pass filtering

2. Averaging

3. Curve smoothing

The first two techniques are performed as data are being read; the third is performed only after all of the data have been collected.

Nonlinear digital filtering is similar to linear digital filtering except that the former is considerahly faster for the same level of accuracy (depending upon the specific uses). The nonlinear filter was used in this case because of timing limitations. The filter is a low-pass type, thus reducing small noise variations in an otherwise constant valued input.

The filter utilized here contains two delays but four zeros! It is this reduced number of delays per zero that accounts for the increased speed of the nonlinear filter. Figure 10 is a general schematic of the nonlinear low-pass filter.

Because the filter is nonlinear, there is an error that increases with the number of zeros used. Four zeros are used in the existing filter because this allows good filtering while still.maintaining minimal nonlinearity errors. The resulting schematic and associated transfer function appear in Figure 11.

The filter is software implemented in the calculator. After passing through the low-pass filter, the data are averaged.

With the averaging technique, eight readings are averaged together, and the result is treated as one data value.

$$
\overline{\mathrm{d}}=\frac{1}{8} \cdot \sum_{\mathrm{i}=1}^{8} \mathrm{~d}_{\mathrm{i}}
$$

After the data have been collected, it is sent on to the minicomputer where the third error-reduction technique is performed.

If the data received from a typical sensor cell were graphed, it might appear as in Figure 12. ${ }^{12}$

It would be desirable to "smooth" out the curve such that it appears more continuous, as in Figure 13.

To accomplish this task, a seven-point smoothing technique (cubic approximation) is utilized. ${ }^{13}$ Seven consecutive data points are considered in a best-fit cubic, which tends to smooth out the curve relative to the neighboring points.

Once the random errors and noise in the data have been reduced by the three techniqucs bricfly described here, the data are linearized (if necessary) 
RFP-2914

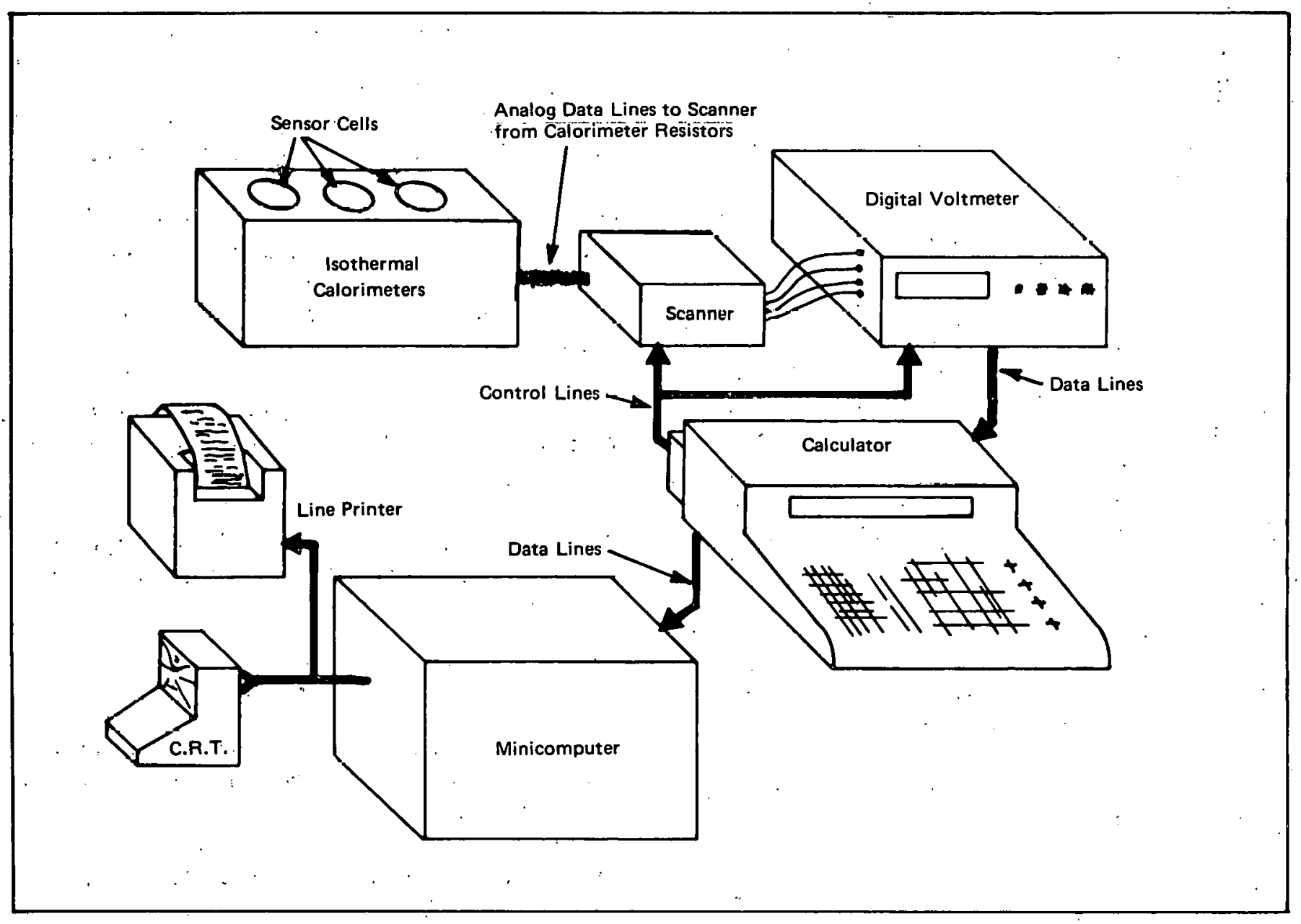

. FIGURE 9. Components Arrangement of a Calorimeter System 
RFP-2914

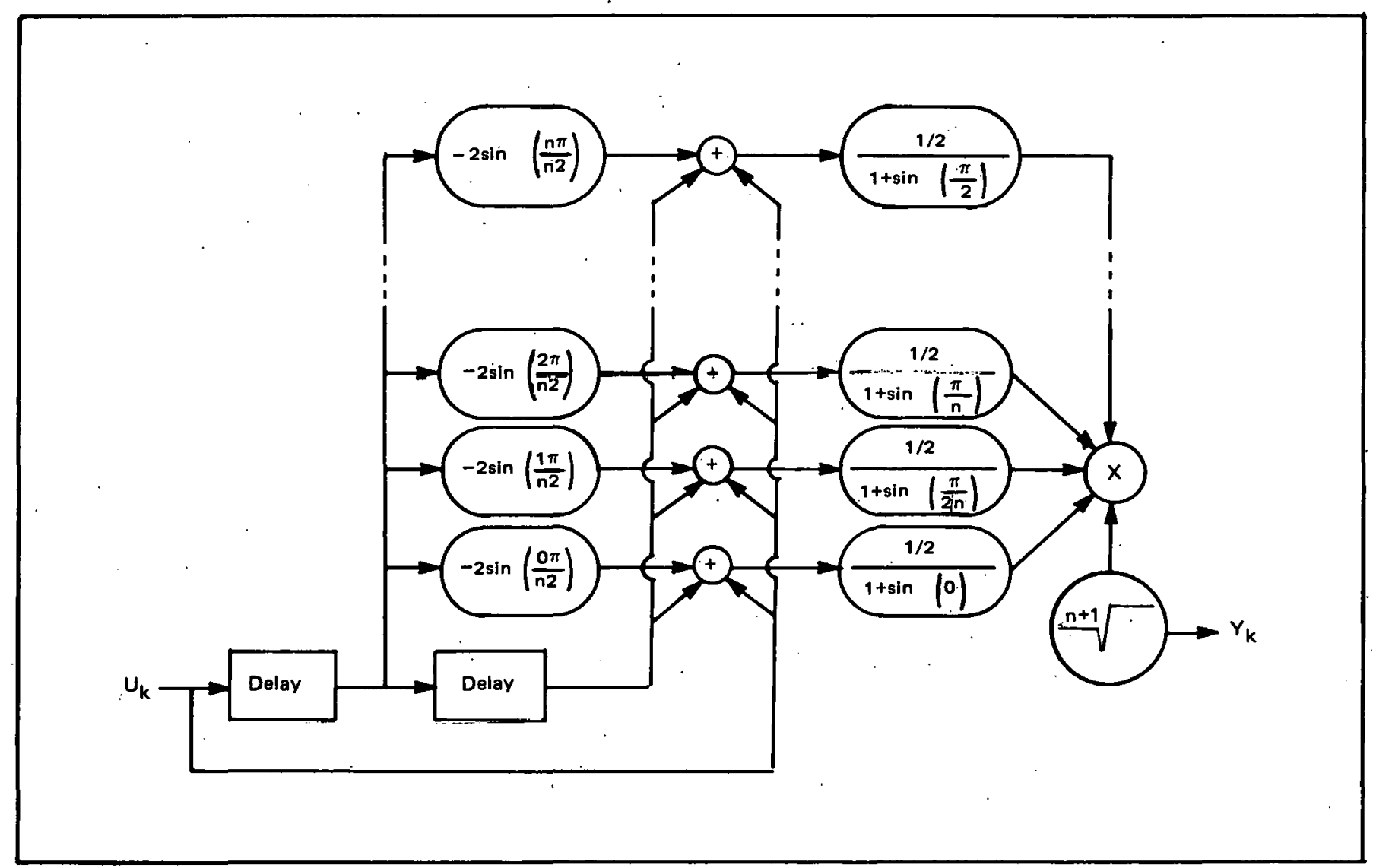

FIGURE 10. Nonlinear Low-Pass Filter With $\eta+1$ Zeros 
RFP-2914
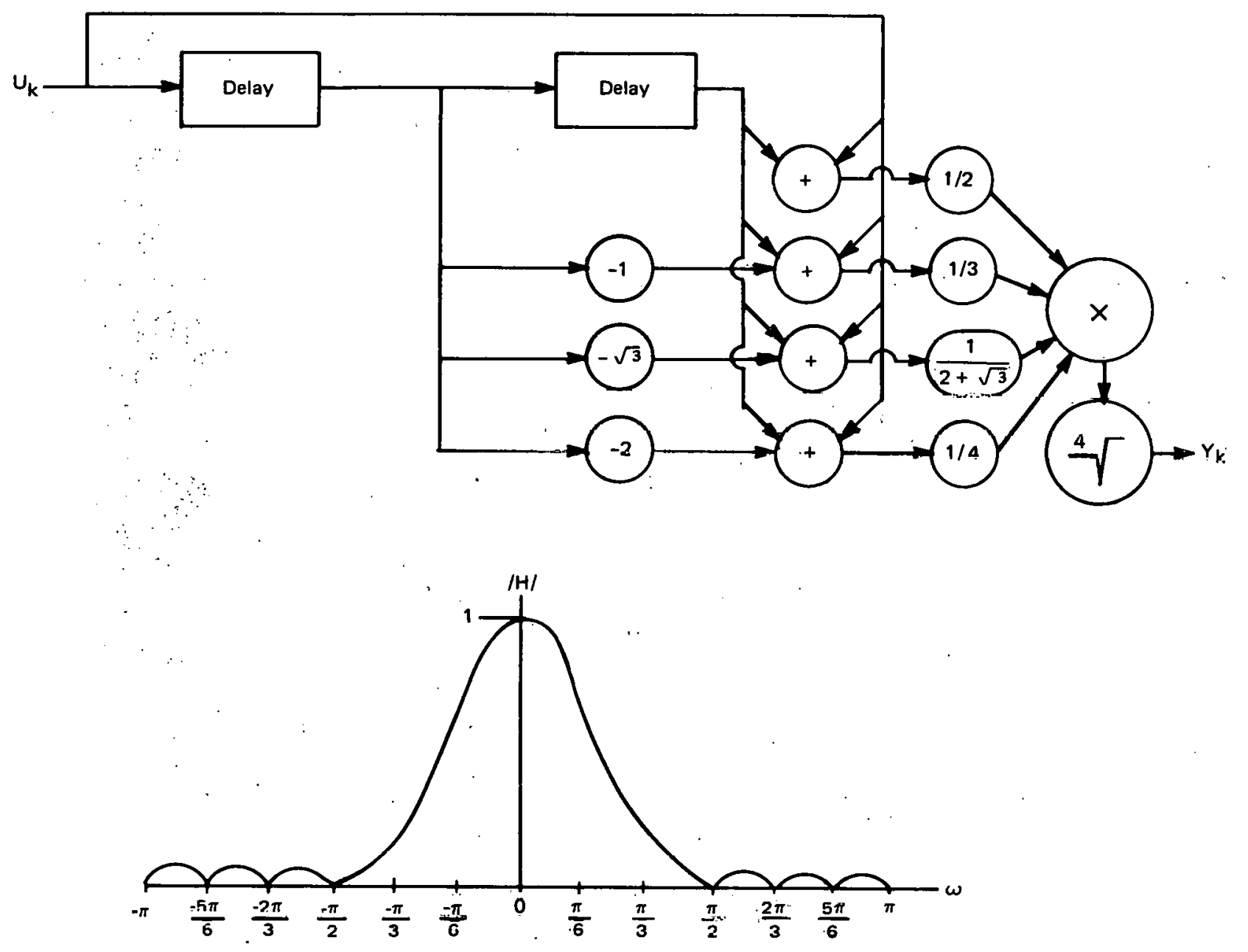

FIGURE 11. Realization of a Four Zeros Nonlinear Low Pass Filter

FIGURE 12. Hypothetical Representation of Actual Data With Noise

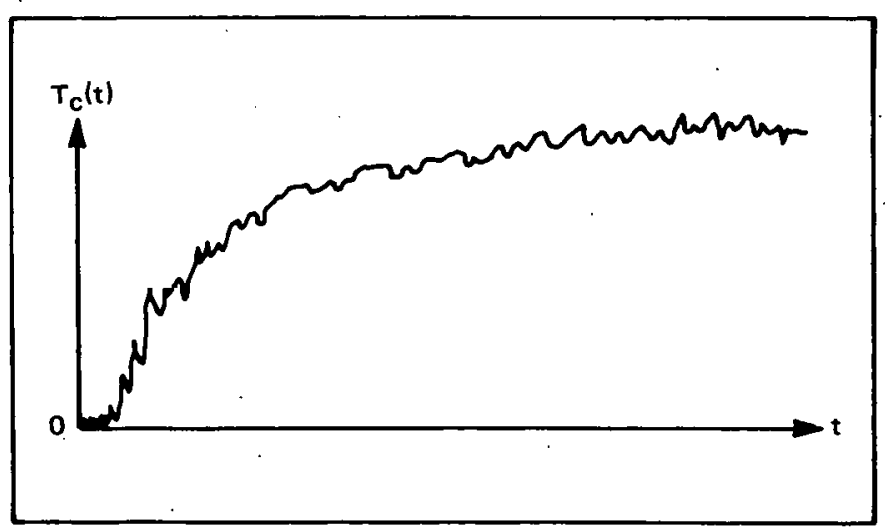

FIGURE 13. Effect of Smoothing the Curve

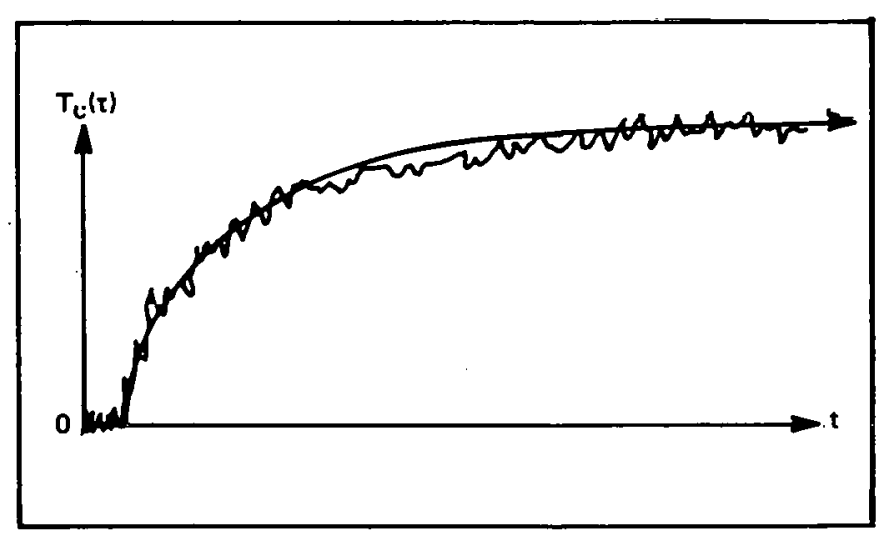


and the end-point equations are applied. Equations 4,20 , and 25 , as follows, are used in this particular software, and the operator can select which of these equations will be used for evaluation of the data.

$$
\begin{gathered}
A=\frac{T_{c}\left(t_{1}\right) T_{c}\left(t_{3}\right)-T_{c}^{2}\left(t_{2}\right)}{T_{c}\left(t_{1}\right)+T_{c}\left(t_{3}\right)-2 T_{c}\left(t_{2}\right)} \\
\left(t_{1}-t_{2}\right)=\left(t_{2}-t_{3}\right) \\
T_{c}(t)=\Lambda[1-\Psi(t)]
\end{gathered}
$$

where $\Psi(0)=1$, and

$$
\Psi\left(t_{0}\right)=(1-\mu)+\frac{\sigma\left(e^{\frac{-(1-\mu)^{2}}{2 \sigma^{2}}}-e^{\frac{-\mu^{2}}{2 \sigma^{2}}}\right)}{\sqrt{2 \pi}\left[F\left(\frac{\mu}{\sigma}\right)-F\left(\frac{\mu-1}{\sigma}\right)\right]} .
$$

and in general

$$
\begin{aligned}
\Psi\left(t+2 t_{0}\right)= & \left(1+\frac{t}{t_{0}}\right) \sigma^{2} \Psi(t) \\
& +(1-\mu) \Psi\left(t+t_{0}\right) \\
& -\frac{\sigma e^{\frac{-\mu^{2}}{2 \sigma^{2}}}}{\sqrt{2 \pi}\left[F\left(\frac{\mu}{\sigma}\right)-F\left(\frac{\mu-1}{\sigma}\right)\right]}
\end{aligned}
$$

$t_{0}$ is chosen as 1 for this program.

$$
\begin{aligned}
& \left(\mathrm{f}_{4}-\mathrm{f}_{5}\right)-\left(\mathrm{f}_{3}-\mathrm{f}_{4}\right)\left(\eta^{3}+\eta^{2}+\eta\right) \\
& -\left(\mathrm{f}_{2}-\mathrm{f}_{3}\right)\left(\eta^{5}+\eta^{4}+\eta^{3}\right) \\
& -\left(\mathrm{f}_{1}-\mathrm{f}_{2}\right) \eta^{6}=0 \\
& \quad\left[\mathrm{f}_{4}-\mathrm{f}_{3}\left(\eta^{3}+\eta^{2}+\eta\right)\right. \\
& \left.+\mathrm{f}_{2}\left(\eta^{5}+\eta^{4}+\eta^{3}\right)-\mathrm{f}_{1} \eta^{6}\right] /[(1-\eta) \\
& \left.\quad \times\left(1-\eta^{2}\right)\left(1-\eta^{3}\right)\right]=A
\end{aligned}
$$

Equation 20 is used to determine the value of $\Lambda$ (equivalent to $\mathrm{A}$ in Equations 4 and 25) by means of curve-fitting the equation to the data and adjusting $\Lambda, \sigma$, and $\mu$ to acquire a best fit. Equations 4 and 25 yield the value of $A$, given the required dala points.
Three equations are included because none of these three equations covers all possible situations, and it may be the case that while two of the equations fail to yield a correct. answer, the third may. Experience with various types and configurations of heat sources will tell which equation is most likely to produce the most accurate results. Allocation has been made in the software such that the operator may choose which particular method is desired for each calorimeter cell (eight cells are observed simultaneously by the calculator).

Although the quantity of experimental data is still limited, all results obtained thus far have proven to be accurate with substantially reduced evaluation times. ${ }^{14}$ Further data collecting is necessary for a complete evaluation. The results should prove quite favorable. Some details concerning the mathematical analysis and other promising endpoint prediction techniques that were developed while this papor was being written have not been included here. Should the reader desire additional information, he may obtain it by consulting either Rockwell International or the author. ${ }^{15}$

\section{NOTES}

1. Information dealing with power output versus mass of radioactive materials can be found in a 1975 report by the American National Standards Institute, Inc., entitled Calibration Techniques for the Calorimetric Assay of Plutonium-Bearing Solids Applied to Nuclear Materials Control.

2. The time to reach equilibrium to within the measuring capabilities of present day instruments varies from under 5 hours to over 36 hours.

3. The particular calorimeter being described and used in this assessment was fully described by G. P. Minges of the Rocky Flats Plant through personal communications. The nonlinearity of the resistive coil being described here is less than 0.1 percent.

4. This equation also appears in a report by C. L. Fellers and P. W. Seabaugh of Mound Laboratory entitled Prediction of Calorimeter Equilibrium. The equation shows a basic heat flow result. 
5. The simple exponential curiously is the solution to most electronics problems, simple fluid flow problems, grow th problems, some economic problems, many physics problems, and even some psychology problems dealing with memory.

6. A treatment of state variable solutions is found on page 110 of Signals and Linear Systems by R. A. Gabel and R. A. Roberts (1973).

7. This equation also appears in a rcport by C. L. Fellers and P. W. Seabaugh of Mound Laboratory entitled Prediction of Calurimeter Equilibrium.

8. The difficulty encountered when using an exponential set such as the one described in Equation 9 is that the sum of $m$ exponentials over some finite period of time form an orthogonal set. It would be possible to choose exponential functions such that a best fit is obtained over the period of time that data were being collected. There is no guarantee, however, that the extrapolation of the result will result in a correct equilibrium prediction. It is therefore necessary to choose exponentials such that they initally approximate the actual exponentials.

Between Equation 5 and Equation 8, a number of more subtle steps in the derivation have been omitted so that more important steps could be expressed. For additional detail, please consult the author.

9. The delta function is defined by its usc in an integral.

Given $f(x)$ continuous at $x=x_{0}$

$$
\int_{-\infty}^{\infty} f(x) \delta\left(x-x_{0}\right) d x=f\left(x_{0}\right)
$$

10. $F(X)$ is the area under the Gaussian curve from $-\infty$ to $X$, where the mean is zero and the standard deviation is 1 . See Elements of Probability Theory by Petr Beckmann (1967, 1968 by Harcourt, Brace, and World, Inc.).
11. The system briefly described here belongs to the Instrumentation and Statistical Systems Laboratory, Rockwell International, Golden, CO.

12. This curve is derived from observations of actual data.

13. This technique is detailed in an article in Analy tical Chemistry, Vol. 36, No. 8 (July 1964), p. 1627. The authors are A. Savitzky and J. M. E. Golay.

14. Data collection time for all samples has been 200 minutes. Errors have been generally in the 1 percent or better range. Samples that normally require perhaps 24 to 36 hours to equilibrate gencrate the largest etror. It will most likely be necessary to increase the data compilation time so as to improve accuracy.

15. The author may be contacted by writing M. A. Fox 6360 E. Floyd Drive Denver, Colorado 80222

\section{BIBLIOGRAPHY}

1. American National Standard, Calibration Techniques for the Calorimetric Assay of Plutonium-Bearing Solids Applied to Nuclear Materials Control, by the American National Standards Institute, Inc., 197.5.

2. Signals and l.inear Systems by R.A. Gabel and R. A. Roberts, p. 110, (1973).

3. A nalytical Chemistry, Vol. 36, No. 8, p. 1627, by A. Savitzky and J. M. E. Golay, July 1964.

4. Elements of Applied Probability Theory by Petr Beckmann, Published by Harcourt, Brace, and World, Inc., 1967, 1968.

5. Prediction of Calorimeter Equilibrium, C. L. Fellers and P. W. Seabaugh of Monsanto Research Corp., Mound Laboratory. 